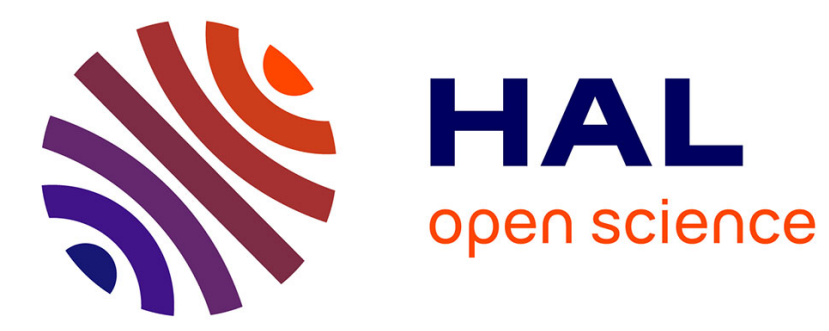

\title{
Atom transfer radical polymerisation of styrene controlled by phosphine-containing coordination compounds of Mo(III)/Mo(IV)
}

François Stoffelbach, Jérôme Claverie, Rinaldo Poli

\section{- To cite this version:}

François Stoffelbach, Jérôme Claverie, Rinaldo Poli. Atom transfer radical polymerisation of styrene controlled by phosphine-containing coordination compounds of $\mathrm{Mo}(\mathrm{III}) / \mathrm{Mo}(\mathrm{IV})$. Comptes Rendus. Chimie, 2002, 5 (1), pp.37-42. 10.1016/S1631-0748(02)01306-1 . hal-03284557

\section{HAL Id: hal-03284557 \\ https://hal.science/hal-03284557}

Submitted on 20 Jul 2021

HAL is a multi-disciplinary open access archive for the deposit and dissemination of scientific research documents, whether they are published or not. The documents may come from teaching and research institutions in France or abroad, or from public or private research centers.
L'archive ouverte pluridisciplinaire HAL, est destinée au dépôt et à la diffusion de documents scientifiques de niveau recherche, publiés ou non, émanant des établissements d'enseignement et de recherche français ou étrangers, des laboratoires publics ou privés. 


\section{Atom Transfer Radical Polymerization of Styrene Controlled by Phosphine-Containing Coordination Compounds of Mo(III)/Mo(IV)}

François Stoffelbach, ${ }^{\mathrm{a}}$ Jerome Claverie, ${ }^{\mathrm{b}}$ Rinaldo Poli ${ }^{\mathrm{a} *}$

${ }^{a}$ Laboratoire de Synthèse et d'Electrosynthèse Organométalliques, Faculté des Sciences "Gabriel", Université de Bourgogne, 6 Boulevard Gabriel, 21000 Dijon, France

${ }^{b}$ Laboratoire de Chimie des Procédés de Polymérisation, LCPP/CPE-CNRS

43, Boulevard du 11 Novembre 1918, 69616 Villeurbanne, France

* To whom correspondence should be addressed.

Tel: $+33-3-80-39-68-81$

Fax: +33-3-80-39-60-98

E-mail: Rinaldo.Poli@u-bourgogne.fr 
Abstract - A controlled polymerization of styrene has been achieved under ATRP conditions by using a phosphine-containing $\mathrm{Mo}^{\mathrm{III}} / \mathrm{Mo}^{\mathrm{IV}}$ system. Linearity of the $\mathrm{M}_{\mathrm{n}} v s$. conversion plot and low PDI's are observed in bulk, in a $30 \%(\mathrm{v} / \mathrm{v}) \mathrm{PhCl}$ solution, and in a chain extension experiment when using $\mathrm{MoCl}_{3}\left(\mathrm{PMe}_{3}\right)_{3} / \mathrm{BIB}$. Controlled polymerization is also observed for a reverse ATRP experiment starting from $\mathrm{MoCl}_{4}\left(\mathrm{PMe}_{3}\right)_{3} / \mathrm{AIBN}$. The absence of chain transfer and termination is confirmed by NMR and MALDI-TOF analyses of polymers obtained by employing BEB and BIB as initiators.

Keywords - Atom Transfer, Molybdenum, Polymerization, Radical, Styrene

\section{Résumé - Version française abrégée - Polymérisation radicalaire par transfert d'atome du styrène contrôlée par des composés de coordination de Mo(III)/Mo(IV) contenant des} ligands phosphines. Cet article décrit la possibilité d'effectuer une polymérisation contrôlée du styrène en utilisant un système de complexes de coordination de $\mathrm{Mo}^{\mathrm{III}} / \mathrm{Mo}^{\mathrm{IV}}$ contenant des ligands phosphines. La propagation procède selon un mécanisme de transfert d'atome par voie radicalaire (ATRP) en utilisant le complexe $\mathrm{MoCl}_{3}\left(\mathrm{PMe}_{3}\right)_{3}$ et l'amorceur $\mathrm{PhCH}(\mathrm{Br}) \mathrm{CH}_{3}$ (BEB). En effet, celui-ci a été prouvé par une série d'expériences : polymérisation en masse et en solution, essais d'extension de chaîne et de catalyse inverse (par utilisation du complexe $\mathrm{MoCl}_{4}\left(\mathrm{PMe}_{3}\right)_{3}$ et une source de radicaux libres, le composé AIBN). Les résultats obtenus montrent une bonne linéarité des masses moléculaires en fonction du taux de conversion du monomère et les indices de polydispersités sont relativement faibles. Des analyses du polymère par RMN et MALDI-TOF-MS ont permis d'exclure la présence de transfert de chaîne et de terminaisons bimoléculaires au cours du processus.

Mots clefs - Molybdène, Polymérisation, Radicaux libres, Styrène, Transfert d'atomes, 


\section{Introduction}

Controlled radical polymerization is becoming a heavily investigated new area of research, in view of the combined tolerance to polar functionalities and the ability to develop well-defined macromolecular architectures $[1,2]$. After the concept of the persistent radical effect (PRE) [3, 4] was fruitfully applied to the development of so-called Stable Free Radical Polymerization (SFRP) methodologies [5-11], the field of controlled radical polymerization has experienced tremendous advances following the independent reports by the groups of Sawamoto and Matyjaszewski $[12,13]$ that the PRE can be realized by an atom transfer process whereby a halogen-capped dormant chain and a metal complex are in fast equilibrium with a reactive free radical and a metal halide complex. This process has been termed Atom Transfer Radical Polymerization (ATRP), see Scheme 1.

In a recent contribution [14], we have applied the analysis of homolytic Bond Dissociation Energies (BDE) to predict the ability of a metal complex to control radical polymerization of styrene. We have shown that, in agreement with the theoretical predictions, a family of $\mathrm{Mo}^{\mathrm{III}} / \mathrm{Mo}^{\mathrm{IV}}$ cyclopentadienyl complexes controls the radical polymerization by both the SFRP and the ATRP protocols, while a system based on $\mathrm{Mo}^{\mathrm{II}} / \mathrm{Mo}^{\mathrm{III}}$ produces a largely insufficient radical concentration to sustain the polymerization process. In addition, the polymerization with $\mathrm{Mo}^{\mathrm{III}} / \mathrm{Mo}^{\mathrm{IV}}$ has been found to be polluted by a side reaction of hydride transfer. The use of a simple kinetic model has allowed to rationalize the variable degree of this Catalytic Chain Transfer (CCT) reaction as a function of reaction conditions (notably the $\mathrm{Mo}^{\mathrm{III}} / \mathrm{Mo}^{\mathrm{IV}}$ ratio) when styrene polymerization is conducted with butadiene-containing cyclopentadienylmolybdenum complexes.

Since the variable of utmost importance for the regulation of the PRE, namely the BDE, appeared quite sensitive to the metal oxidation state but not so much to the nature of the 
ancillary ligands,[14] we wondered whether the controlled radical polymerization of styrene could also be achieved in the presence of cyclopentadienyl-free $\mathrm{Mo}^{\mathrm{III}} / \mathrm{Mo}^{\mathrm{IV}}$ systems. Numerous compounds of type $\mathrm{MoCl}_{3} \mathrm{~L}_{3}$ and $\mathrm{MoCl}_{4} \mathrm{~L}_{\mathrm{n}}(\mathrm{L}=$ ethers, thioethers, phosphines, etc.; $\mathrm{n}==2$ or 3 ) are known [15] and are more easily accessible than the cyclopentadienylcontaining analogues [16]. In this contribution, we report our initial studies indicating that, indeed, polystyrene is obtained by a controlled polymerization procedure under a variety of conditions, with control being exerted by phosphine-containing $\mathrm{Mo}{ }^{\mathrm{III}} / \mathrm{Mo}^{\mathrm{IV}}$ complexes.

\section{Experimental Section}

\subsection{General Remarks}

All manipulations were carried out under an atmosphere of dry and oxygen-free argon with standard Schlenk techniques. Styrene was washed with a aqueous $\mathrm{NaOH}$ solution (10\%), neutralized with water, dried with $\mathrm{MgSO}_{4}$ and then distilled at $25^{\circ} \mathrm{C}$ under reduced pressure. Chlorobenzene was bubbled with dry argon for more than 15 min immediately before use. Molecular weights and molecular weight distributions were measured with a Gynkoteck P580 apparatus using THF as eluent $(1 \mathrm{~mL} / \mathrm{min})$ and being equipped with a refractometer and 2 columns B Jordi DVB (range 1000-1000000). MALDI-TOF mass spectrometric analyses were performed with a Perkin Elmer Voyager - DE STR. The matrix was the Dithranol and PS samples were cationized with silver salt (AgTFA). Compouds $\mathrm{MoCl}_{3}\left(\mathrm{PMe}_{3}\right)_{3}, 1$ [17], and $\mathrm{MoCl}_{4}\left(\mathrm{PMe}_{3}\right)_{3}, 2[16,18]$, were obtained according to previously described synthetic procedures. (1-Bromoethyl)benzene (BEB) and ethyl-2-bromoisobutyrate (BIB) were purchased from Aldrich Chemical Co and degassed prior to use. Azobis(isobutyronitrile) (AIBN) was purchased from JANSSEN and recrystallized twice from MeOH before use. 


\subsection{ATRP polymerizations.}

All ATRP polymerization reactions were performed following the same experimental procedure. The complex was added to a $50 \mathrm{~mL}$ Schlenk tube equipped with a stirring bar. Styrene and the initiator (BEB or BIB) were added to the reaction flask by a syringe. The Schlenk tube was then immersed in an oil bath heated at $90^{\circ} \mathrm{C}$. Aliquots were withdrawn periodically for a reaction monitoring. These were dried by room temperature evaporation followed by oven drying at $100^{\circ} \mathrm{C}$ for $8 \mathrm{~h}$ for the calculation of the conversion. The GPC analyses were carried out on the crude dried polymers after redissolution in THF.

\subsection{Reverse ATRP polymerization.}

Complex 2 and AIBN were added to a $50 \mathrm{~mL}$ Schlenk tube equipped with a stirring bar. Chlorobenzene and styrene were added by a syringe. The Schlenk tube was immersed in an oil bath heated at $120^{\circ} \mathrm{C}$ for $15 \mathrm{~min}$, then it transferred to another bath at $90^{\circ} \mathrm{C}$. Aliquots were withdrawn periodically for a reaction monitoring by GPC, as described above.

\section{Results and Discussion}

Styrene is smoothly polymerized in the presence of compound $\mathbf{1}$ and $\mathrm{PhCH}\left(\mathrm{CH}_{3}\right) \mathrm{Br}$ (BEB) in a $1: 1$ ratio at $90^{\circ}$ in bulk. The progression of polydispersity and number average molecular weight as a function of conversion is shown in Table 1 and graphically in Figure 1. The continuous decrease of PDI as the conversion increases, reaching values under 1.5 at $50 \%$ 
conversion, is as expected in the presence of a PRE. The Mn are quite close to the theoretical values. A similar behavior is observed when the polymerization is conducted in chlorobenzene, see Table 2 and Figure 2. The polymers obtained in solution have slightly lower PDI than those obtained in bulk. The rate of polymerization, on the other hand, is greater for the bulk experiment (see Figure 3), as expected from the increased monomer and radical concentrations.

<Figure 1 and Table 1>

$<$ Figure 2 and Table 2>

$<$ Figure 3>

The absence of chain transfer in this polymerization process has been confirmed by the NMR and MS analyses of the polymer. The ${ }^{1} \mathrm{H}$ NMR spectrum on the polymers obtained at small conversions shows clearly the presence of brominated chain-ends (peak at 4.3-4.6 ppm) [19] and the absence of chains terminated by vinyl groups (for which a resonance would be expected in the 6.0-6.4 ppm range) [20].

A MALDI-TOF-MS analysis of the polymer provides supporting evidence for the presence of Br-terminated chains, but shows also three additional families of polymer chains (see Figure 4a). The position and relative intensities of the four series of peaks are identical with those of the polymer obtained by using the $\mathrm{CpMoCl}_{2}\left(\mathrm{PMe}_{3}\right)_{2} / \mathrm{BEB}$ system and analyzed under the same instrumental conditions [14]. The fours peaks at $\mathrm{m} / \mathrm{z}=3321.7,3337.9$, 3353.5, and 3379.6 in Figure 4a, for instance, are attributed to the formulas $\mathrm{MeCH}(\mathrm{Ph})-(\mathrm{Sty})_{\mathrm{n}^{-}}$ $\mathrm{CH}_{2} \mathrm{CH}(\mathrm{Ph}) \mathrm{Br}+\mathrm{Ag}^{+}, \quad \mathrm{MeCH}(\mathrm{Ph})-(\mathrm{Sty})_{\mathrm{n}+1}-\mathrm{CH}=\mathrm{CH}(\mathrm{Ph})+\mathrm{Ag}^{+}, \quad \mathrm{MeCH}(\mathrm{Ph})-(\mathrm{Sty})_{\mathrm{n}+2^{-}}$ $\mathrm{CH}=\mathrm{CH}(\mathrm{Ph})+\mathrm{Na}^{+}$, and $\mathrm{MeCH}(\mathrm{Ph})-(\mathrm{Sty})_{n+1}-\mathrm{CH}_{2} \mathrm{CH}(\mathrm{Ph}) \mathrm{Cl}+\mathrm{Ag}^{+}$, respectively, with Sty = $\mathrm{CH}_{2} \mathrm{CHPh}$ and $\mathrm{n}=28$. The presence of $\mathrm{Cl}$-terminated chains is not surprising, since the 
radical forming equilibrium (equation 1) can be reversed in principle by abstraction of either a bromine or a chloride atom. However, the Mo-Cl BDE is stronger than the Mo-Br BDE according to our calculations [14], consequently favoring the bromine atom transfer. Indeed, the Cl-terminated chains are less abundant than the Br-terminated chains. The most intense peaks, on the other hand, are those related to vinyl-terminated chains with either $\mathrm{Ag}^{+}$or $\mathrm{Na}^{+}$ being provided by the matrix. Sodium contamination is a common phenomenon for MALDITOF analyses of polymers [21, 22]. The related $\mathrm{Na}$ peaks of the $\mathrm{Br}$ - or Cl-capped polymer chains are either masked by other peaks or too small to be observed.

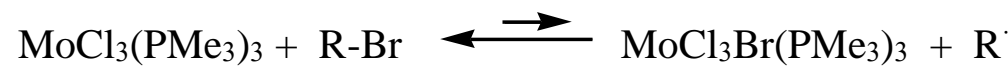

$<$ Figure 4>

The question arises as to the origin of these vinyl-terminated chains. Dehydrobromination processes are known to occur readily for Br-terminated polymers upon contact with the silver salt and the Cl-terminated chains could analogously be dehydrochlorinated. This possibility seems also confirmed by the inability to observe vinylterminated end group resonances in the NMR. However, the alternative of a CCT process remains a possibility, since after the transfer process the resulting metal hydride would, upon insertion of the first styrene monomer, yield the same $\mathrm{CH}_{3} \mathrm{CH}(\mathrm{Ph})$ - end group provided by the BEB initiator. In order to settle this point, the polymerization was repeated with a different initiator, $\mathrm{BIB}$, which differs from $\mathrm{BEB}$ in having 10 additional mass units. The result of the MALDI-TOF-MS analysis of the resulting polymer (see Figure 4b) shows quite clearly that all four families of polymer chains are shifted by exactly 10 mass units and consequently 
demonstrates that they are all initiated by BIB. In other words, there is no CCT in this polymerization process.

A common test for a living polymerization process is also the so-called "stop-and-go" experiment (chain extension). In a genuine "living" polymerization, after the chain growth process is stopped by lowering the temperature or by the complete monomer consumption, resuming the polymerization by warming or by adding new monomer restores the growth of the previously formed chains without initiating any new ones. The results shown in Table 3 and Figure 5 for a polymerization of styrene with 1/BEB clearly show that $(i)$ the polymerization process takes place with the same rate before and after being stopped for ca. $14 \mathrm{~h}$, indicating that the total number of chains is conserved; (ii) the $\mathrm{M}_{\mathrm{n}}$ of the polymers before and after the stop fall on the same line and are close to the theoretical masses; (iii) the PDI continues to decrease after resumption of the polymerization.

$<$ Figure 5 and Table 3>

A final test for the involvement of Equation 1 in determining the PRE for the living polymerization process has been the establishment of a controlled polymerization under "reverse" conditions. That is, equilibrium 1 can in principle be equally established starting from the left hand side, as shown above (regular ATRP process), or from the right hand side by exposing the preformed Mo(IV) complex to a radical (reverse ATRP). Complex $\mathrm{MoCl}_{3} \mathrm{Br}\left(\mathrm{PMe}_{3}\right)_{3}$ does not exist to the best of our knowledge and out attempts to synthesize it by $\mathrm{Br}_{2}$ oxidation of $\mathbf{1}$ have only yielded analytically impure products. However, the related complex $\mathrm{MoCl}_{4}\left(\mathrm{PMe}_{3}\right)_{4}, 2$, is known [18] and we have recently improved its preparation procedure [16]. A reverse ATRP experiment, the initial radical being provided by the thermal decomposition of AIBN, confirms that the polymerization process is controlled under these 
conditions, see Table 4 and Figure 6. The control of the radical concentration would be established by Equilibrium 2. The experimental molecular weight is higher than theoretical molecular weight, indicative that the initiator efficiency (AIBN) is less than 1 . In addition, PDI decreases with conversion, as expected. The successful controlled polymerization under "reverse" ATRP conditions demonstrates that the PRE is established by use of the $\mathrm{Mo} / \mathrm{Mo}^{\mathrm{II}}$ couple.

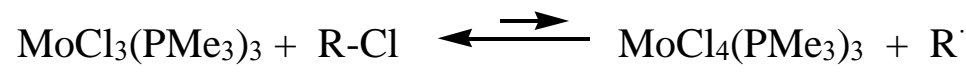

$<$ Figure 6 and Table 4>

Complex $\mathrm{MoCl}_{3}(\mathrm{THF})_{3}$, i.e. the synthetic precursor of complex 1, does not exert any control in the polymerization of styrene. In fact, a faster polymerization process having all the characteristics of cationic polymerization is observed when using this complex. We presume that the Lewis acidity of the Mo(III) center in this coordination compound may favor the opening process of the THF ligand to afford a $\mathrm{Mo}^{\mathrm{IV}}-\mathrm{OCH}_{2} \mathrm{CH}_{2} \mathrm{CH}_{2} \mathrm{CH}_{2}{ }^{+}$moiety faster than the atom transfer process. The zwitterionic species formed would then trigger the cationic polymerization mechanism.

No degree of control is witnessed in the radical polymerization of MMA with 1. The PMMA obtained at low conversions is characterized by a high $\mathrm{M}_{\mathrm{n}}$ and a broad PDI. Our interpretation of this result is that Equilibrium 1 is shifted to a greater extent toward the right end side when $\mathrm{R}^{\prime}=\left(\right.$ Polymer- $\left.\mathrm{CH}_{2}\right)\left(\mathrm{CH}_{3}\right) \mathrm{C}^{\prime}-\mathrm{COOCH}_{3}$, in agreement with a lower BDE of the corresponding $\mathrm{C}-\mathrm{Br}$ bond and an uncontrolled radical polymerization caused by a large radical concentration. 


\section{Conclusions and Perspectives}

In conclusion, we have reported here for the first time that the ATRP polymerization of styrene can be accomplished by simple coordination compounds of molybdenum, the PRE being established by a redox couple containing $\mathrm{Mo}^{\mathrm{III}}$ and $\mathrm{Mo}^{\mathrm{IV}}$ species. A controlled radical polymerization of styrene has been accomplished by using the lithium molybdate(V) complexes [LiMo(NAr) $\left.)_{\dot{e}}(C-N) \mathrm{R}\right]\left(C-N=\mathrm{C}_{6} \mathrm{H}_{4}\left(\mathrm{CH}_{2} \mathrm{NMe}_{2}\right)-2 ; \mathrm{Ar}=\mathrm{C}_{6} \mathrm{H}_{3} \operatorname{Pr}^{\mathrm{i}}{ }_{2}-2,6 ; \mathrm{R}=C-N\right.$, $\mathrm{Me}, \mathrm{CH}_{2} \mathrm{SiMe}_{3}, p$-Tol) and benzyl chloride as initiator [23]. The direct implication of the Mo complex in the polymerization control mechanism was not unambiguously proven in that case, however. Current studies are aimed at the modification of the metal coordination sphere for achieving control in the radical polymerization of other monomers.

\section{Acknowledgments}

We are grateful to the CNRS for support this work (Programme Catalyse pour l'Industrie et l'Environnement) and for a BDI Ph.D. fellowship to F.S. Support from the Ministery of Research and COST D17 (Working group on Transition Metal Mediated Living Radical Polymerization) is also gratefully acknowledged.

\section{References}

[1] K. Matyjaszewski, Controlled Radical Polymerization (1998),, American Chemical Society, Washington DC.

[2] T. E. Patten, K. Matyjaszewski, Acc. Chem. Res. 32, (1999), 895-903.

[3] H. Fischer, J. Am. Chem. Soc. 108, (1986), 3925-3927. 
[4] H. Fischer, Macromolecules 30, (1997), 5666-5672.

[5] D. H. Solomon, E. Rizzardo, P. Cacioli, EP 135280 (1985), Chem. Abs. 85, (1985), P25381t.

[6] E. Rizzardo, Chem. Aust. 54, (1987), 32-43.

[7] L. D. Arvanatitopoulos, M. P. Greuel, H. J. Harwood, Am. Chem. Soc., Polym. Prep. 34, (1994), 549-551.

[8] B. Wayland, G. Poszmick, S. Mukerjee, J. Am. Chem. Soc. 116, (1994), 7943-7944.

[9] J. Claverie, Res. Disc. 416, (1998), 1595-1604.

[10] D. Benoit, S. Grimaldi, S. Robin, J. P. Finet, P. Tordo, Y. Gnanou, J. Am. Chem. Soc. 122, (2000), 5929-5939.

[11] D. Benoit, E. Harth, P. Fox, R. M. Waymouth, C. J. Hawker, Macromolecules 33, (2000), 363-370.

[12] M. Kato, M. Kamigaito, M. Sawamoto, T. Higashimura, Macromolecules 28, (1995), 1721-1723.

[13] J.-S. Wang, K. Matyjaszewski, J. Am. Chem. Soc. 117, (1995), 5614-5615.

[14] E. Le Grognec, J. Claverie, R. Poli, J. Am. Chem. Soc., (in press).

[15] G. Wilkinson, R. D. Gillard, J. A. McCleverty, Comprehensive Coordination Chemistry (1988),, Pergamon Press, Oxford.

[16] F. Stoffelbach, D. Saurenz, R. Poli, Eur. J. Inorg. Chem., (in press).

[17] J. L. Atwood, W. E. Hunter, E. Carmona-Guzman, G. Wilkinson, J. Chem. Soc., Dalton Trans., (1980), 467-470.

[18] R. D. Rogers, E. Carmona, A. Galindo, J. L. Atwood, L. G. Canada, J. Organomet. Chem. 277, (1984), 403-415.

[19] K. Matyjaszewski, S. Coca, Y. Nakagawa, J. Xia, Polym. Mat. Sci. Eng. 76, (1997), 147-162. 
[20] G. E. Roberts, J. P. A. Heuts, T. P. Davis, Macromolecules 33, (2000), 7765-7768.

[21] M. A. Dourges, B. B. Charleux, J.-P. Vairon, J.-C. Blais, G. Bolbach, J.-C. Tabet, Macromolecules 32, (1999), 2495-2502.

[22] M. Bednarek, T. Biedroni, P. Kubisa, Macromol. Chem. Phys. 201, (2000), 58-66.

[23] J. A. M. Brandts, P. van de Geijn, E. E. van Faassen, J. Boersma, G. van Koten, J. Organometal. Chem. 584, (1999), 246-253. 
Table 1. Results of the ATRP of styrene in bulk with $\mathrm{MoCl}_{3}\left(\mathrm{PMe}_{3}\right)_{3}$ and BEB. T $=90^{\circ} \mathrm{C},[$ styrene $] /[\mathrm{BEB}] /[\mathrm{Mo}]=196 / 1 / 1$.

\begin{tabular}{lllll}
\hline Time (min) & Conversion $(\%)$ & $\mathrm{M}_{\mathrm{n}}($ exp.) & $\mathrm{M}_{\mathrm{n}}$ (theoret.) & PDI \\
\hline 262 & 17,0 & 3752 & 3460 & 1,6 \\
580 & 24.3 & 4867 & 4968 & 1,5 \\
1025 & 36,8 & 5873 & 7505 & 1,5 \\
1317 & 47,5 & 7538 & 9698 & 1,5 \\
1625 & 55,4 & 9197 & 11301 & 1,4 \\
\hline
\end{tabular}

Table 2. Results of the ATRP of styrene in $\mathrm{PhCl}$ solution (30\% v/v) with $\mathrm{MoCl}_{3}\left(\mathrm{PMe}_{3}\right)_{3}$ and BEB. $\mathrm{T}=90^{\circ} \mathrm{C},[$ styrene $] /[\mathrm{BEB}] /[\mathrm{Mo}]=235 / 1 / 1$.

\begin{tabular}{lllll}
\hline Time $(\min )$ & Conversion $(\%)$ & $\mathrm{M}_{\mathrm{n}}(\mathrm{exp})$. & $\mathrm{M}_{\mathrm{n}}$ (theoret.) & PDI \\
\hline 385 & 18,9 & 6388 & 4617 & 1,5 \\
1072 & 24.3 & 7396 & 7108 & 1,5 \\
1332 & 34,5 & 7473 & 8442 & 1,5 \\
1702 & 37,3 & 8103 & 9129 & 1,4 \\
3181 & 49 & 10095 & 12000 & 1,3 \\
\hline
\end{tabular}

Table 3. Results of the stop-and-go ATRP of styrene in bulk with $\mathrm{MoCl}_{3}\left(\mathrm{PMe}_{3}\right)_{3}$ and BEB. T $=90^{\circ} \mathrm{C},[$ styrene $] /[\mathrm{BEB}] /[\mathrm{Mo}]=239 / 1 / 1 .^{\mathrm{a}}$

\begin{tabular}{lllll}
\hline Time (min) & Conversion $(\%)$ & $\mathrm{M}_{\mathrm{n}}(\mathrm{exp})$. & $\mathrm{M}_{\mathrm{n}}$ (theoret.) & PDI \\
\hline 150 & 11.7 & 4097 & 2903 & 2 \\
303 & 24.3 & 4693 & 3666 & 1.7 \\
425 & 17.6 & 4747 & 4365 & 1.8 \\
565 & 20.1 & 5682 & 4994 & 1.7 \\
740 & 23 & 6574 & 5717 & 1.6 \\
1580 & 22.9 & 5719 & 5696 & 1.7 \\
1775 & 26.9 & 7119 & 6680 & 1.6 \\
1985 & 30.3 & 7981 & 7526 & 1.5 \\
2105 & 31.9 & 7706 & 7938 & 1.5 \\
\hline
\end{tabular}

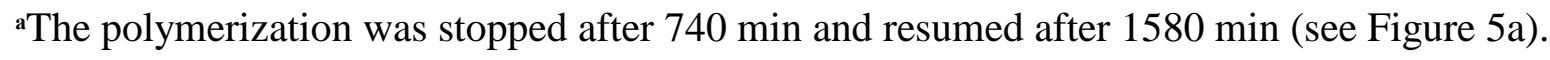


Table 4. Results of the reverse ATRP of styrene in bulk with $\mathrm{MoCl}_{4}\left(\mathrm{PMe}_{3}\right)_{3}$ and AIBN. T $=120^{\circ} \mathrm{C}$ for $15 \mathrm{~min}$, then $\mathrm{T}=90^{\circ} \mathrm{C} ;[$ styrene $] /[\mathrm{AIBN}] /[\mathrm{Mo}]=240 / 0.5 / 1$.

\begin{tabular}{lllll}
\hline Time (min) & Conversion $(\%)$ & $\mathrm{M}_{\mathrm{n}}(\mathrm{exp})$. & $\mathrm{M}_{\mathrm{n}}$ (theoret.) & PDI \\
\hline 488 & 18.2 & 7895 & 4147 & 2.3 \\
1373 & 29.6 & 9350 & 7382 & 2.0 \\
2123 & 38.1 & 11206 & 9507 & 1.9 \\
5643 & 55.2 & 15080 & 13764 & 1.6 \\
\hline
\end{tabular}




\section{Captions for Figures.}

Figure 1. Plot of $\mathrm{M}_{\mathrm{n}}$ (black squares) and PDI (open triangles) vs. conversion for the ATRP of styrene in bulk with complex 1. The straight line corresponds to the theoretical $\mathrm{M}_{\mathrm{n}}$ for a living polymerization. Conditions are as in Figure 3.

Figure 2. Plot of $\mathrm{M}_{\mathrm{n}}$ (black squares) and PDI (open triangles) vs. conversion for the ATRP of styrene in $\mathrm{PhCl}$ solution with complex 1. The straight line corresponds to the theoretical $\mathrm{M}_{\mathrm{n}}$ for a living polymerization. Conditions are as in Figure 3.

Figure 3. Plots of $\ln \left([\mathrm{M}]_{0} /[\mathrm{M}]\right)$ vs. time for the bulk and solution $(30 \% \mathrm{v} / \mathrm{v}$ in $\mathrm{PhCl})$ ATRP of styrene with complex 1. Conditions: $\mathrm{T}=90^{\circ} \mathrm{C}$; $[$ styrene $] /[\mathrm{BEB}] /[\mathrm{Mo}]=$ 196/1/1 (bulk), 235/1/1 ( $\mathrm{PhCl}$ solution).

Figure 4. Details of the MALDI-TOF spectra for polystyrene obtained using BEB (a) or BIB (b) as initiator.

Figure 5. Plots of (a) conversion vs. time and (b) $\mathrm{M}_{\mathrm{n}}$ (black squares) and PDI (open triangles) vs. conversion for the stop-and-go ATRP of styrene in bulk. The straight line corresponds to the theoretical $\mathrm{M}_{\mathrm{n}}$ for a living polymerization. Conditions: $\mathrm{T}=90^{\circ} \mathrm{C},[$ styrene $] /[\mathrm{BEB}] /[\mathrm{Mo}]=239 / 1 / 1$. 
Figure 6. Plot of $\mathrm{M}_{\mathbf{n}}$ (black squares) and PDI (open triangles) vs. conversion for the reverse ATRP of styrene in bulk. The straight line corresponds to the theoretical $M_{n}$ for a living polymerization. Conditions: $\mathrm{T}=120^{\circ} \mathrm{C}$ for $15 \mathrm{~min}$, then $\mathrm{T}=90^{\circ} \mathrm{C}$; [styrene]/[AIBN]/[Mo] = 240/0.5/1 . 
Figure 1

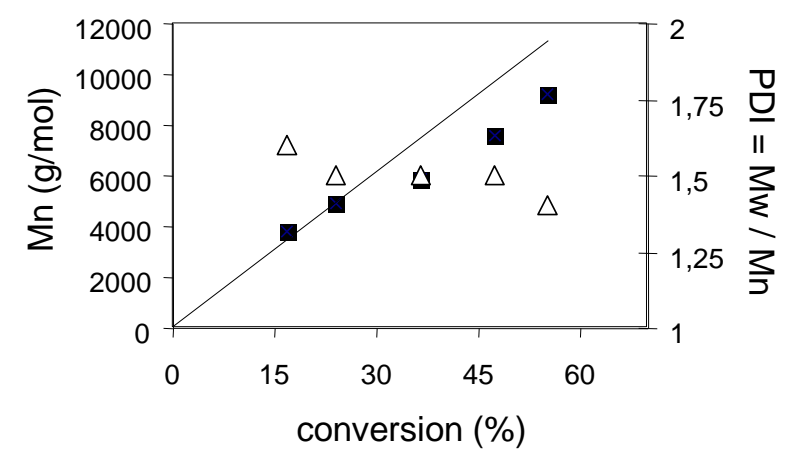

Figure 2

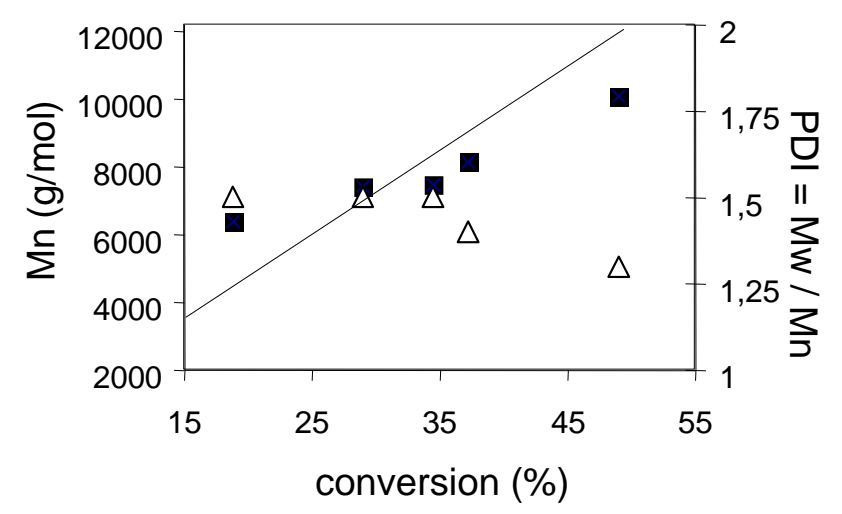

Figure 3

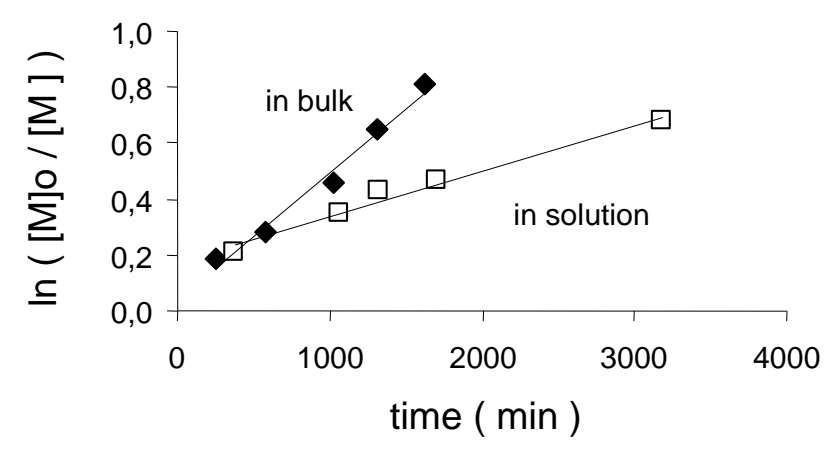


Figure 4
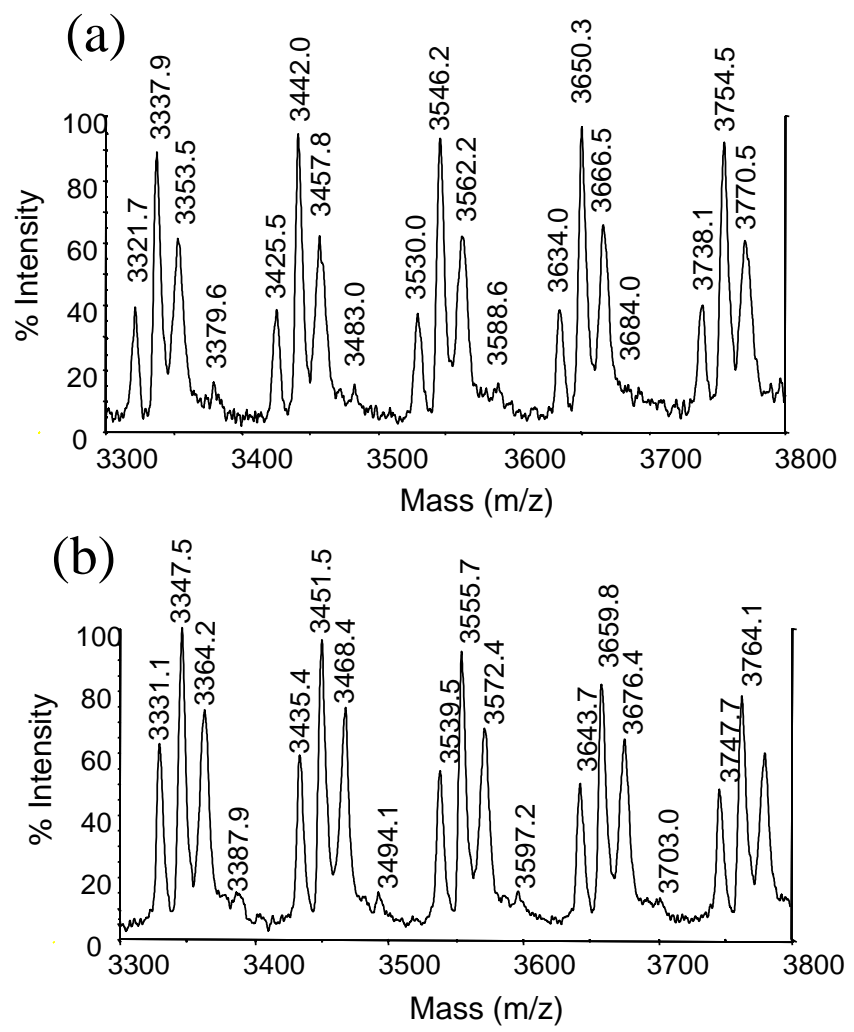
Figure 5

(a)

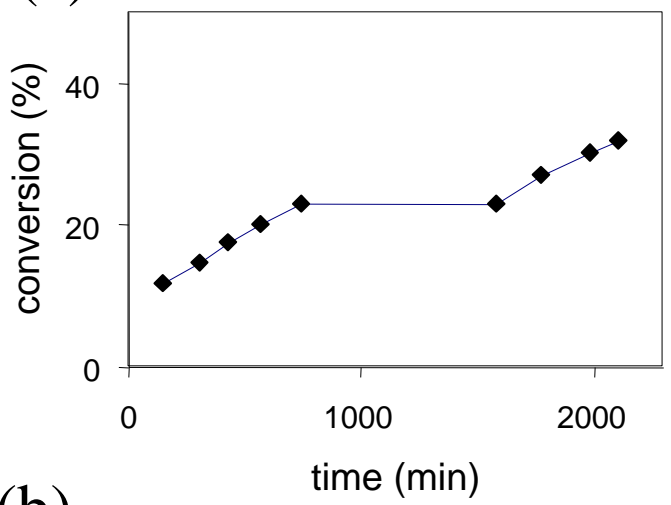

(b)

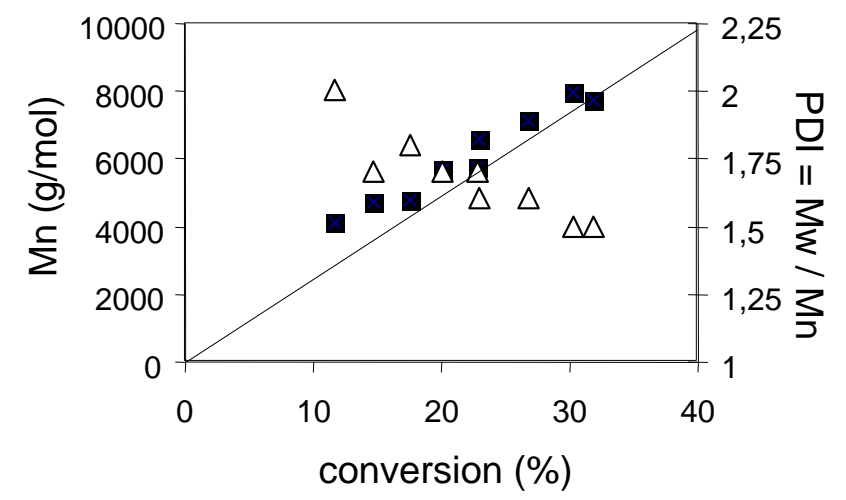

Figure 6

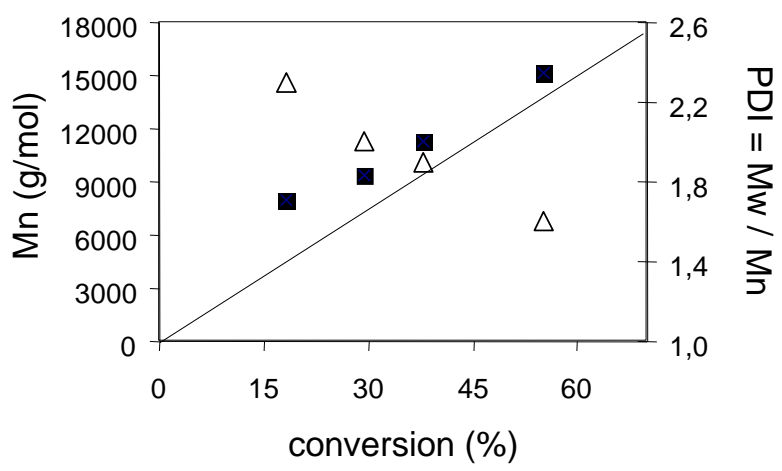




\section{Scheme 1}

$$
\mathrm{M}^{\mathrm{n}}+\mathrm{R} \longrightarrow \mathrm{X} \underset{k_{+}^{\prime}}{\stackrel{k^{\prime}-}{\longrightarrow}} \mathrm{M}^{\mathrm{n}+1} \longrightarrow \mathrm{X}+k_{\mathrm{p}}^{\left.(\mathrm{x} 2)\right|_{k_{\mathrm{t}}}}+\overbrace{\begin{array}{c}
\text { bimolecular } \\
\text { termination } \\
\text { reactions }
\end{array}}^{\mathrm{R}}
$$

